\title{
Los horizontes de la izquierda y la geopolítica actual bajo la lente agonista. Mouffe, Chantal. (2014). Agonística: Pensar el mundo políticamente. Buenos Aires: Fondo de Cultura Económica. 246 pp.
}

\author{
Víctor Castrelo*
}

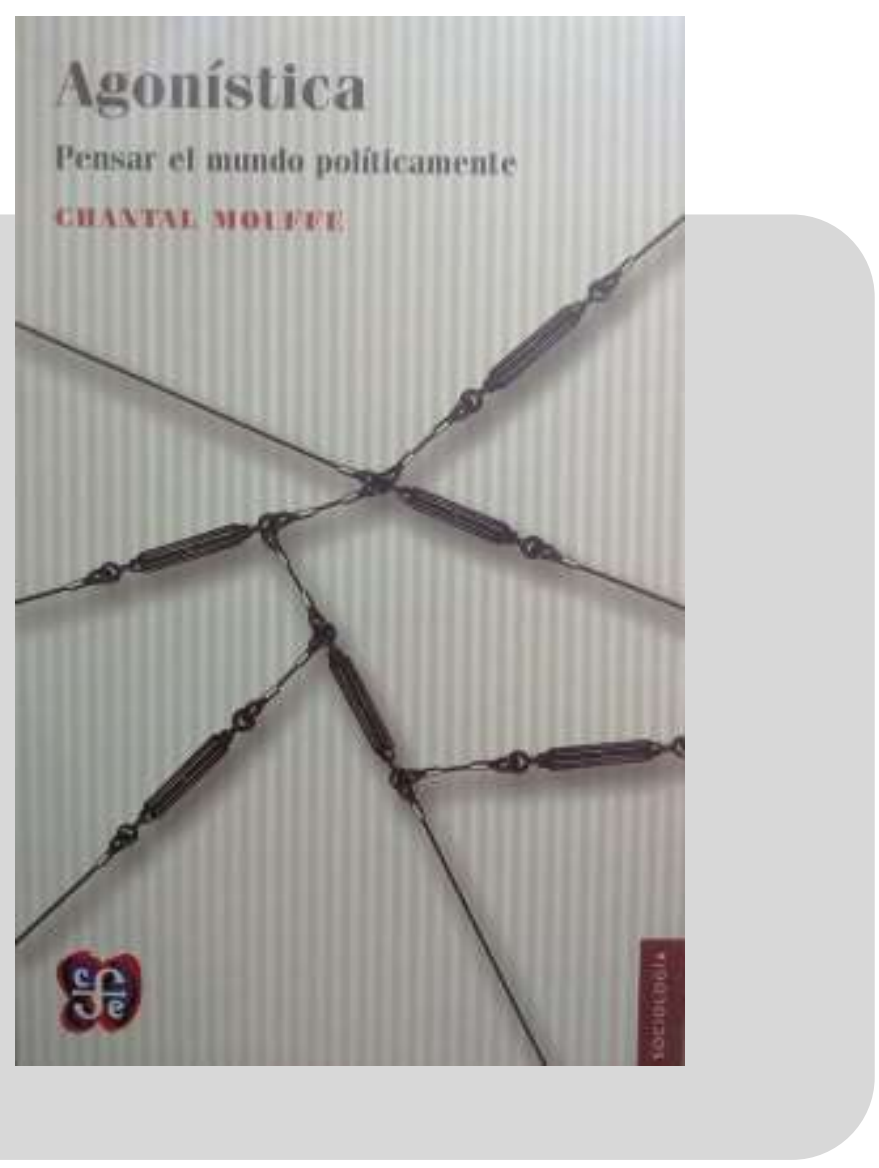

\footnotetext{
* Licenciado en Sociología (FaHCE-UNLP), realizando estudios de Doctorado en Ciencias Sociales (FaHCEUNLP). Correo electrónico: vitocastrelo@gmail.com
} 
1.

En uno de los libros más actuales y urgentes de toda su obra, Chantal Mouffe exhorta a pensarlo todo en términos de hegemonía y agonismo. Las preocupaciones de la autora belga bajan desde las cumbres de la teoría política para insertarse en la situación internacional actual a lo largo de cinco ensayos recientes -a los que se suma una entrevista más antigua realizada por Elke Wagner- donde se trazan diversos objetivos y temas que sobrevuelan una cuestión común: ofrecer un programa político orientador ante un mundo en estado de ebullición. De ahí que Agonística. Pensar el mundo políticamente se yergue como una obra crucial para pensar fenómenos sociales tan diversos y complejos como el movimiento de Indignados en España, las protestas estudiantiles en Chile, la cuestión musulmana en la Francia actual o la irrupción de ISIS en Oriente Medio. La necesidad de efectuar un rescate de las identidades (políticas, nacionales, culturales) ante el riesgo de su dilución en un universalismo cosmopolita es la preocupación fundante que recorre estas 146 páginas.

2.

Nada más comenzar la lectura de Agonística constatamos cómo la autora vuelve sobre viejos adversarios para pensar los temas de estos tiempos; para esto, recalca las bases ontológicas de su pensamiento, donde "aceptar la negatividad radical implica no solo reconocer que el pueblo es múltiple, sino también que está dividido" (2014: 17). La imposibilidad de eliminar el antagonismo constituye la base sobre la cual se apoyan todas las reflexiones sucesivas, es decir, la idea de que el mundo social posee una naturaleza pluralista que trae consigo conflictos que no pueden alcanzar jamás una solución racional final. Si en Habermas el interés pasa por alcanzar un acuerdo intersubjetivo a partir de un intercambio de argumentos en el marco de normativas lógico-racionales (disputarien), en el pensamiento de la teoría de la hegemonía lo importante será cómo establecer un modelo de democracia que funcione de modo tal que los conflictos y sus protagonistas dejen de ser enemigos para transformarse en adversarios que eviten la persecución de la eliminación mutua, es decir, en que el conflicto no se elimina, sino que se sublima. De acuerdo con el diagnóstico de Mouffe, la primacía del pensamiento liberal, que en la teoría política de izquierda está encarnado por Habermas, entre otros, es lo que paradójicamente condujo a un recrudecimiento de los antagonismos, los cuales se presentan de modos cada vez más violentos.

Ahora bien, si la hegemonía del pensamiento liberal condujo a este estado de cosas ¿cuál es la alternativa viable que puede ofrecer la izquierda? la respuesta será siempre la misma: agonismo. A nivel internacional la globalización no sería más que la máscara detrás de la cual se ubica Occidente y su vocación hegemonizante que impone una lógica neoliberal unipolar avasallante de consecuencias atroces no solo en términos 
económicos, sino también políticos y sociales. Lejos de signar un armonioso fin de la historia, el colapso soviético y los aires de legitimidad, universalidad e irrevocabilidad de este 'cosmopolitismo' son terreno fértil para el florecimiento de nuevos antagonismos cuyos modos de expresarse asumen formas sangrientas. El avance occidental es percibido como una amenaza por comunidades con códigos religiosos y formas de ordenamiento social distintas y fuertemente arraigadas, en muchos casos la reacción ante dicha amenaza a la propia identidad asume formas de fanatismo religioso que decantan en la violencia extrema. Esta es una manera de pensar en términos hegemónicos la feroz irrupción del Estado Islámico (ISIS) en Oriente Medio.

La salida agonista propuesta por Mouffe ante lo que acabamos de mencionar consiste en reemplazar el actual esquema de relaciones internacionales asentado en un modelo unipolar con eje en Estados Unidos por un modelo multipolar donde una diversidad de polos que se relacionan entre sí sin que ninguno de ellos tenga la pretensión de ser el polo superior establezcan una confrontación agonista, es decir, la posibilidad de rivalizar sin tener que eliminarse. Dicho modelo debe asumir el costo de tolerar polos que no sean democráticos $\mathrm{O}$, al menos, democráticos en un sentido occidental de democracia liberal aceptando que existen sociedades cuyo derecho a seguir trayectorias acordes a la especificidad de sus tradiciones debe ser respetado. ¿Es el modelo multipolar capaz de clausurar los conflictos internacionales? No, pero puede sublimarlos reconduciéndolos desde el antagonismo hacia el agonismo. Ahora bien, posiblemente esta sea la idea más rica y a la vez más controvertida de todos los ensayos: un esquema mundial multipolar ¿debe emprenderse a cualquier costo? ¿Es aceptable que lo integren comunidades cuyo orden político está lejos, no solo de la democracia liberal, sino de cualquier forma de democracia? Este es el punto central a discutir del pensamiento de Mouffe y, probablemente, el flanco por donde se filtren las críticas más duras provenientes del racionalismo consensual.

Los fines de Mouffe por lo general transitan dos dimensiones: la política y la teórica. En Agonística esto está más presente que nunca. La cuestión política está ligada a la posibilidad de reconstruir un programa de izquierdas que sea orientador para emergentes de la crisis neoliberal tales como el movimiento de estudiantes chilenos de quienes Mouffe celebra la decisión de participar en la política tradicional con Camila Vallejo a la cabeza o los Indignados del movimiento 15M en España (lo mismo aplica al Occupy estadounidense), quienes reciben un poco alentador diagnóstico dada su opción por la estrategia de la deserción proveniente de Hardt y Negri. Estos dos autores son denominados 'los teóricos de la deserción' (o 'del éxodo'), en tanto promueven un modelo (anti) político que rechaza de lleno los vínculos de la 'multitud' con los canales institucionales de la política tradicional para, en lugar de llevar en ese ámbito la 'guerra de posición', esperar simplemente que las contradicciones hagan estallar al 'Imperio'. El pensamiento de Mouffe marca las limitaciones de esta 
perspectiva a la cual opone su agonismo: debe haber un involucramiento crítico con las instituciones, porque si se sigue al pie de la letra la prospectiva de Hardt y Negri el resultado es que el vacío dejado por fuerzas progresistas en su abandono del Estado y las instituciones puede ser llenado por sectores de la derecha. Es plausible considerar que la autora da en la tecla si pensamos en la Europa actual donde el repliegue de la socialdemocracia y los vacíos dejados por los movimientos guiados por la estrategia de la deserción son ocupados por expresiones políticas xenófobas y hasta neonazis, tales como UKIP en Inglaterra y PEGIDA en Alemania. El caso de Francia es paradójico: el vacío no solo fue ocupado por la xenofobia antimusulmana del Frente Nacional de Marine Le Pen, sino también por su opuesto, que se manifiesta cada vez más fuertemente con los miles de jóvenes franceses pertenecientes a sectores populares que, carentes de representación, adoptan una identidad religiosa asentada en el islamismo, muchas veces fanático. Europa refleja claramente los dos problemas más importantes: por un lado, la hegemonía del modelo de consenso racional que desdibuja las fronteras izquierda/derecha licuando así las identidades políticas y, por otro lado, la escasa posibilidad de influenciar en las decisiones de gobierno que tienen los movimientos de protesta surgidos al calor de la crisis financiera, si mantienen su enfoque antiinstitucional. En contrapartida, la emergencia de Syriza en la política griega, su decisión de ingresar a la política institucional participando de elecciones generales, así como el camino que parece seguir Podemos en España parecen ser los primeros indicios -y frutos- de la revisión crítica de la izquierda respecto de la estrategia de la deserción y el éxodo en tanto no rechazan de plano al Estado y a las instituciones democráticas tradicionales, sino que apuntan a participar en ellas para transformarlas.

3.

Como señalábamos al comienzo, se trata de la obra más urgente de Mouffe en tanto busca incidir efectivamente en el Zeitgeist de estos días, teniendo como objetivo central la recomposición de un proyecto sociopolítico de izquierda, para el cual las identidades políticas colectivas y su dimensión afectiva deben tomar un papel protagónico y resistir ante la amenaza de su dilución. Una alternativa a la globalización neoliberal es posible, si se desarticulan sus prácticas hegemónicas y luego se articulan varios niveles de prácticas diferentes que den lugar a un nuevo orden social, tal como ha venido sucediendo con los gobiernos progresistas asentados en Latinoamérica en los últimos quince años, donde se lograron desarticular una multiplicidad de prácticas hegemónicas neoliberales desde el Estado -aunque no solo desde él- y así transformaron en gran medida la situación de sus sociedades. En tal sentido, la reciente victoria del partido griego Syriza, embanderado en el rechazo a las políticas de austeridad impuestas por la troika europea, así como la creciente relevancia que está 
De Prácticas y discursos/ Universidad Nacional del Nordeste/ Centro de Estudios Sociales

Año 4, Número 4, 2015

ISSN 2250-6942

adquiriendo Podemos marcan un horizonte esperanzador para la izquierda, si pensamos la política en términos hegemónicos y agonísticos. 